\section{Book a dental study tour for 2021, risk-free}

Book a new travel experience in 2021 on a dental study tour, with opportunities to discover new destinations and cultures as well as earning valuable CPD points. JBT dental study tours are led by specialists in their fields and include professional programmes offering real insight into dentistry through wide ranging visits, talks and opportunities to meet with your counterparts in other countries.

JBT's forthcoming dental tours include the combined Medical and Dental Study Tour to Iceland (15-24 May 2021) (pictured), a Dental Study Tour to China (17-27 May 2021) and a Dental Study Tour to Ecuador and the Galapagos Islands (3-15 September 2021). More details at www.jonbainestours.com.

To make it as easy as possible to look ahead, JBT is waiving its nonrefundable deposit. You can now book on any 2021 tour with a fully refundable deposit. The deposit is fully refundable until the due date of the first instalment payment (three months before tour departure). At that time the tour will revert to normal booking terms and you

\section{Confirmed effectiveness in controlling viruses}

IQAir Cleanroom 250 air purifier's effectiveness in controlling viruses has now been officially confirmed by the European accredited test institute Airmid Healthgroup in Ireland.

The test report confirms that the IQAir Cleanroom 250 high performance air cleaner achieved a $99.9 \%$ reduction of airborne viruses in less than ten minutes in a room of nearly $30 \mathrm{~m} 3$.

On the highest speed setting, the viral load was reduced from above $2790 \mathrm{ng} / \mathrm{m} 3$ to below the detectable measure of $0.156 \mathrm{ng} /$ m3 - a $99.99 \%$ reduction.

The virus used in the test is the $\mathrm{H} 1 \mathrm{~N} 1$ viruses, which is identical in size range to SARS-CoV-2.

Using IQAir high-performance air purifiers to minimise viral pollution is particularly recommended after aerosol-generating treatments. The use of the IQAir Cleanroom 250 air purifier can protect both personnel and subsequent patients from severe viral exposure.

For further information, visit www.haguedental.com, email info@haguedental.com or call 08002985005.

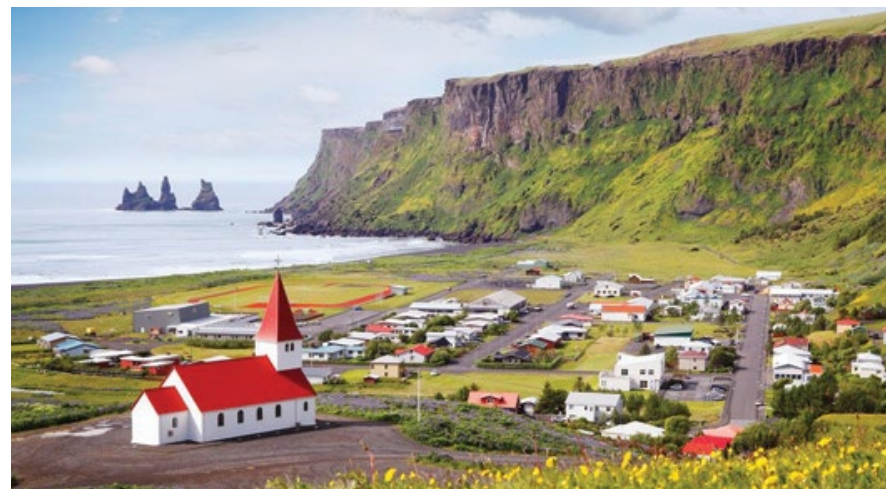

have the option to commit to the tour. This means that you can book any 2021 tour, right now, with absolutely no financial risk.

Contact Jon Baines Tours on +44 (0)20 72239485 info@ jonbainestours.co.uk.

\section{Safeguard your livelihood}

When it comes to your livelihood you must leave nothing to chance. That is why you need income protection - a policy designed to pay you an income if you are unable to work due to sickness, injury or an accident.

Not sure which policy to go for? The team of independent financial advisers at money4dentists can work with you to determine which plan would be best for you, taking into consideration factors such as your affordability and health status.

Using their expertise, the team will also be able to help you decide which level of incapacity cover would best suit you - own occupation, any occupation or suited occupation - as well as choose between a guaranteed or reviewable premium.

Should you need advice about any other health insurances, money4dentists can help with that too; just pick up the phone today.

For more information call 08453455060 or 0754DENTIST.

Email info@money4dentists.com or visit www. money4dentists.com.

\title{
Optimum hygiene needs the right tools
}

It has never been clearer that we must give our patients all the tools they need to support their oral health and wellbeing.

Correct twice-daily brushing, including interdental cleaning, is the foundation of oral hygiene. Brushes from leading brand TANDEX come in different sizes, with each size having a specific colour, so once you have helped your patient find the right one for them, selection is easy.

The range includes everyday brushes, also the unique TANDEX FLEXI interdental brush, with its ergonomic handle and robust yet flexible design, combining comfort and function.

Is it time to try TANDEX?

For more information on Tandex's range of products, visit www. tandex.dk.

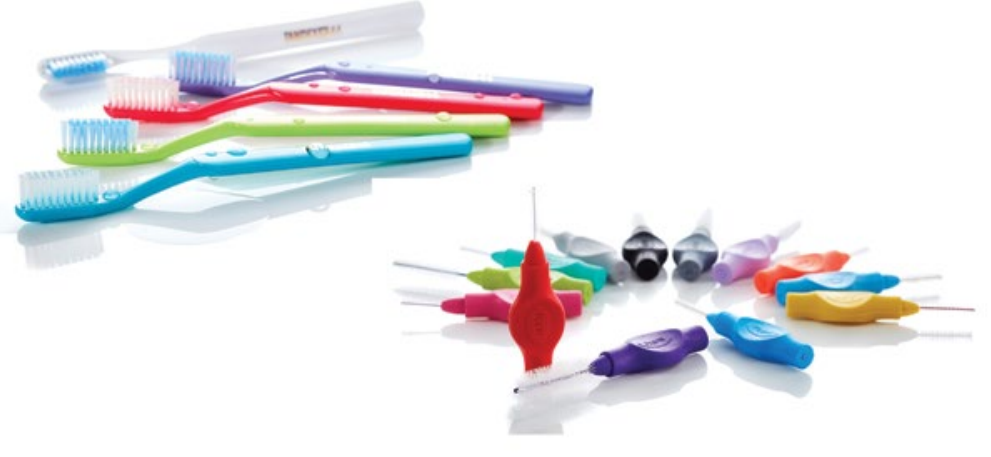

